\title{
Non-cognitive skills and the parent-child relationship: A cross-sectional study
}

\author{
Hiromi Suzuki 1 ${ }^{1,}$, Nobuyuki Miyatake ${ }^{1}$, Takashi Kusaka ${ }^{2}$ \\ 1 Department of Hygiene, Faculty of Medicine, Kagawa University, Kita-gun, Kagawa 761-0793, Japan; \\ miyarin@med.kagawa-u.ac.jp \\ 2 Department of Pediatrics, Faculty of Medicine, Kagawa University, Kita-gun, Kagawa 761-0793, Japan; \\ kusaka@med.kagawa-u.ac.jp \\ * Correspondence: tanzuki@med.kagawa-u.ac.jp; Tel.: +81-87-891-2465; Fax: +81-87-891-2134
}

\begin{abstract}
Background and Objectives: Non-cognitive skills (NCS) are vital components of a socially and financially successful life. They are developed through childhood education, family and school environments, and social settings. The aim of this study was to examine the associations between NCS and the parent-child relationship, mental health, and lifestyle at school and at home for adolescents. Materials and Methods: An internet-based survey was conducted with 1,566 mothers and their children (aged 14) in Japan. Survey items for the children included background (i.e., sociodemographic items, school achievements, and lifestyle), NCS (i.e., grit and self-control scales), and mental health, while their mothers provided social, financial, and educational information, and information on parent-child relationships, including descriptions of the fathers and the father-child relationship. Results: Parent-child relationships were mostly good (i.e., $90.9 \%$ for mothers and $75.6 \%$ for fathers), with bad relationships being less common (1.6\% for mothers and $6.7 \%$ for fathers). Adolescent lifestyle parameters and mental health were significantly associated with grit and selfcontrol. Adolescents with good parent-child relationships had significantly higher NCS scores regardless of the gender of the parent. Higher NCS scores were significantly associated with better parent-child relationships, more favorable lifestyles, and better mental health among adolescents. Conclusions: These findings imply that good parent-child relationships may aid in the development of adolescents' NCS, thereby facilitating positive lifestyles at school and home.
\end{abstract}

Keywords: adolescent; grit; non-cognitive skills; parent-child relationship; self-control

\section{Introduction}

Non-cognitive skills (NCS) are vital elements for achieving academic success, physical wellbeing, and financial stability [1]. In 2006, economist James Heckman also highlighted the important role of NCS in economic development [2]. NCS have been defined in various ways. One of these definitions is based on the "Big Five" (i.e., neuroticism, extraversion, conscientiousness, openness to experience, and agreeableness), which is a widely used framework in psychology [3]. Other NCS include motivation, perseverance, and self-control [4]. Psychologist Angela Duckworth suggested "grit" as one of the most important NCS for personal success, defined as a combination of passion and perseverance in dealing with long-term goals [5]. Grit and self-control scales have been internationally validated and widely used to evaluate NCS in numerous recent studies.

Many cross-sectional, longitudinal, and interventional studies, including those using a randomized controlled trial method, have investigated the effects of NCS. For example, some studies explored how NCS predict academic achievement in adolescents [6-12]. The cognitive skills represented by academic achievement and NCS are separate items, but are closely interrelated [12]. NCS such as grit and self-control are important determinants for accomplishing goals (e.g., 
academic achievement) because success requires individuals to regulate their attention and behavior while avoiding temptation (i.e., self-control) and continuing to make efforts despite setbacks (i.e., grit) [13].

Childhood NCS have been found to also affect outcomes in adulthood. For instance, childhood self-control can predict academic achievement as well as physical health, financial status, and public safety in adulthood [14]. The High Scope Perry Preschool Program and Carolina Abecedarian Project have also provided evidence supporting the contribution of NCS to socioeconomic success, better health, and lower crime and drug-abuse rates as well as academic achievement [6, 15, 16] (https://highscope.org/perry-preschool-project/ accessed January, 2019), (https://abc.fpg.unc.edu/abecedarian-project accessed January, 2019). These programs focus on high-quality childhood education by developing characteristics and behaviors that are valued in the labor market [1]. Heckman suggested that early childhood education was the most cost-effective intervention for developing NCS, generating economic productivity, and creating social wellbeing [6].

A meta-analysis provided evidence that NCS play a role in promoting academic achievement in addition to improving the psychosocial, cognitive, and language domains; however, these results were not always consistent [17]. Many such studies have applied a variety of interventions, ranging from child- and teacher-focused curricula to interventions with more multidimensional content including the parent, child, and teacher. However, the effectiveness of NCS interventions varied and the most effective intervention is yet to be identified [17].

In addition to childhood education, the family environment is an important factor for child development $[1,18]$. Heckman suggested the importance of parent-child interactions, noting that successful interventions should "emulate the mentoring and attachment that successful families give their children" [1]. It is not yet clear what is precisely required in the family environment to promote the development of NCS. However, "mentoring and attachment" may be key, as these elements represent the parent-child relationship as a simple but important developmental factor. However, no previous studies examining NCS have focused on the parent-child relationship. This study therefore explored this relationship's effect on NCS.

\section{Materials and Methods}

Study design.

We performed an observational cross-sectional study. Participants were voluntarily recruited through an internet-based research company. All participants indicated their informed consent to participate by submitting an online questionnaire. This study was approved by the Ethical Committee Registry of the Faculty of Medicine Kagawa University (Heisei 27-221, March 28, 2016) and conducted in accordance with the principles described in the Helsinki Declaration.

\section{Study population.}

The study sample included 1,566 pairs of mothers and their children (783 for each gender). Child participants were aged 14-15 and were attending their 8th year of school in Japan. An internet-based research company was used to access eligible samples throughout Japan before distributing a self-administered online questionnaire. Respondents received online shopping coupons as rewards for their participation. Mothers and their children were required to answer the 
questionnaires in the same room at the same time. Mothers thus confirmed whether their children were available and could proceed with the questionnaire. Those who could not meet these requirements were excluded from the study. The investigation was conducted in April 2016.

\section{Questionnaire.}

The questionnaire was divided in two parts: the first for mothers and the second for their children. Mothers answered questions about their marital status and annual household income. They also answered questions about the age, work hours, and educational background of both mothers and fathers. Mothers then assessed both their relationship with the child and the relationship between the child and the father on a 3-point Likert-type scale (i.e., 1 = good, 2 = neither good nor poor, 3 = poor). The children answered questions about their demographic and lifestyle characteristics (e.g., gender, number of siblings, academic achievements, after-school activities, school attendance, screen time, and sleep time), non-cognitive skills (i.e., grit and self-control scales), and mental health (depression scale).

Non-cognitive skills.

NCS were evaluated according to two scales. The Grit-S scale (including the Perseverance of Effort and Consistency of Interest subscales) contains eight statements rated on a 5-point Likerttype scale (i.e., 1 = not like me at all, 5 = very much like me). Items include the following: “New ideas and projects sometimes distract me from previous ones," "I am a hard worker," "I have difficulty maintaining my focus on projects that take more than a few months to complete," and "I finish whatever I begin" [19, 20]. The other NCS scale we used was the Brief Self-Control Scale, which contains 13 items rated on a 5-point Likert-type scale (i.e., $1=$ not like me at all, $5=$ very much like me). Items include the following: "I have a hard time breaking my bad habits," "I am lazy," "I am able to work effectively toward long-term goals," and "I often act without thinking through all the alternatives" [21, 22]. Both scales were rated as having good validity and reliability in both Japanese and English [19-22].

Mental health.

Mental health was evaluated according to the Birleson Depression Self-Rating Scale for Children (DSRS-C), which is designed for use among respondents aged 7 years and older. It contains 18 items rated on a 3-point Likert-type scale (i.e., $0=$ always, $1=$ sometimes, and $2=$ not at all) $[23,24]$. The total score thus ranges from 0 to 36. Depression is indicated by a total score of 16 or above. Items are related to positive attitudes (e.g., "I have lots of energy"), negative feelings (e.g., "I feel very lonely" and "I think life is not worth living"), and symptoms affected by mental status (e.g., insomnia or stomach ache). The DSRS-C showed good validity and reliability in both Japanese and English [23, 24].

Statistical analysis.

Continuous variables were summarized using means and standard deviations (e.g., grit, selfcontrol, and DSRS-C scores), while categorical variables were presented as absolute numbers and relative percentages (e.g., gender, annual income, and educational background of parents). Exploratory analyses were conducted to compare NCS according to lifestyle parameters: ANOVA 
was used for variables with three levels and a t test for those with two levels. The relationship between NCS and the parent-child relationship was examined using an ANOVA and TukeyKramer HSD test, while Spearman's correlation was used to examine the relationship between mental health scores and NCS. Missing values were not estimated in this study. All analyses were performed using JMP Pro 13.2.1 for Windows (SAS Institute, Cary, USA) (p values of less than 0.05 indicated statistical significance).

\section{Results}

This study surveyed 1,566 mother-child pairs. Respondent background information is presented in Table 1.

Table 1. Child and parent backgrounds

\begin{tabular}{|c|c|}
\hline$N=1566$ & $\begin{array}{l}\mathrm{n}(\%) \text { or } \\
\text { mean } \pm \mathrm{SD}\end{array}$ \\
\hline Boys & $783(50)$ \\
\hline \multicolumn{2}{|l|}{ Academic achievement } \\
\hline Good & $557(35.6)$ \\
\hline Average & $714(45.6)$ \\
\hline Poor & $265(16.9)$ \\
\hline \multicolumn{2}{|l|}{ Sleep time (per night) } \\
\hline Less than 6 hours & $188(12.0)$ \\
\hline 6-8 hours & $1271(81.2)$ \\
\hline More than 8 hours & $101(6.5)$ \\
\hline \multicolumn{2}{|l|}{ After-school activities } \\
\hline Sports & $971(62.0)$ \\
\hline Other activities & $466(29.1)$ \\
\hline Has a good friend & $1486(94.9)$ \\
\hline School absenteeism & $20(1.3)$ \\
\hline Mental health scale & $10.5 \pm 5.5$ \\
\hline Has depression & $290(18.5)$ \\
\hline Self-control & $2.97 \pm 0.64$ \\
\hline Grit & $3.07 \pm 0.60$ \\
\hline Has developmental disabilities & $61(3.9)$ \\
\hline Single parent & $184(11.8)$ \\
\hline \multicolumn{2}{|l|}{ Household annual income } \\
\hline$<2.5$ million yen & $132(8.5)$ \\
\hline $2.5-5$ million yen & $420(26.8)$ \\
\hline 5-10 million yen & $791(50.5)$ \\
\hline >10 million yen & $223(14.2)$ \\
\hline \multicolumn{2}{|l|}{ University graduates } \\
\hline Mother & $414(26.4)$ \\
\hline Father & $684(49.5)$ \\
\hline \multicolumn{2}{|l|}{ Relationship with mother } \\
\hline Good & $1,423(90.9)$ \\
\hline
\end{tabular}


Neither good nor poor

Poor

Relationship with father

Good

Neither good nor poor

Poor

$\mathrm{SD}$, standard deviation
$118(7.5)$

$25(1.6)$

$1,044(75.6)$

245 (17.7)

93 (6.7)

Table 2. Self-control and grit scores according to gender

\begin{tabular}{lllll}
\hline $\mathrm{N}=1566$ & $\begin{array}{l}\text { Boys }(783) \\
(\text { Mean } \pm \mathrm{SD})\end{array}$ & $\begin{array}{l}\text { Girls } \\
(\text { Mean } \pm \mathrm{SD})\end{array}$ & $\begin{array}{l}(783) \\
\mathrm{p} \text { values }\end{array}$ & \\
\hline Self-control & $2.87 \pm 0.62$ & $3.06 \pm 0.64$ & $<0.0001$ \\
Grit & $3.01 \pm 0.59$ & $3.34 \pm 0.59$ & $<0.0001$ \\
\hline
\end{tabular}

SD, standard deviation.

There was a total of 783 boys ( $50 \%$ of the children sampled); the mean mental health score was $10.5 \pm$ 5.5 , with 290 children (18.5\% of the total sample) having scores indicating depression. Mean NCS scores were $3.07 \pm 0.60$ for grit and $2.97 \pm 0.64$ for self-control. Girls showed significantly better scores for both grit and self-control than boys. (Table 2, Figure 1). Mother-child relationships were mostly good (90.9\%; only $1.6 \%$ indicated a bad relationship). On the other hand, $75.6 \%$ of all father-child relationships were good (6.7\% reported a bad relationship) (Table 1$)$.

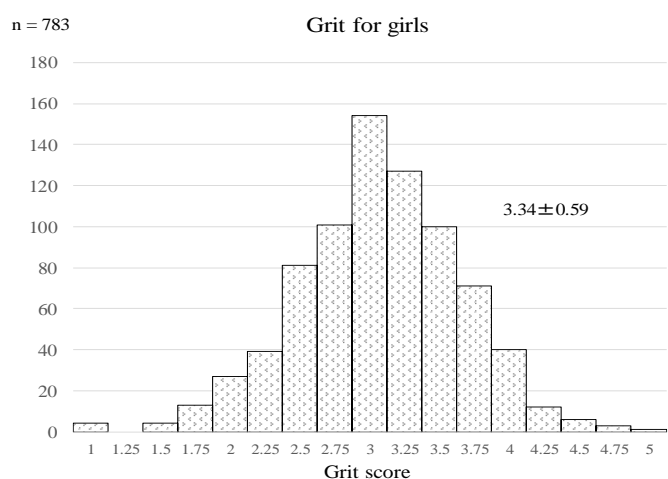

(a)

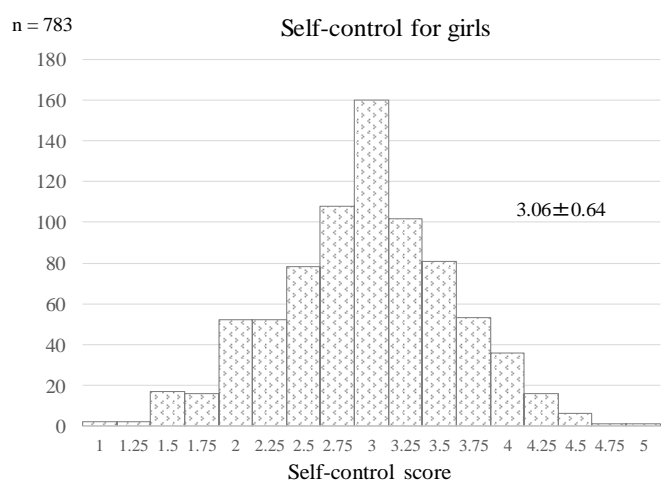

(c)

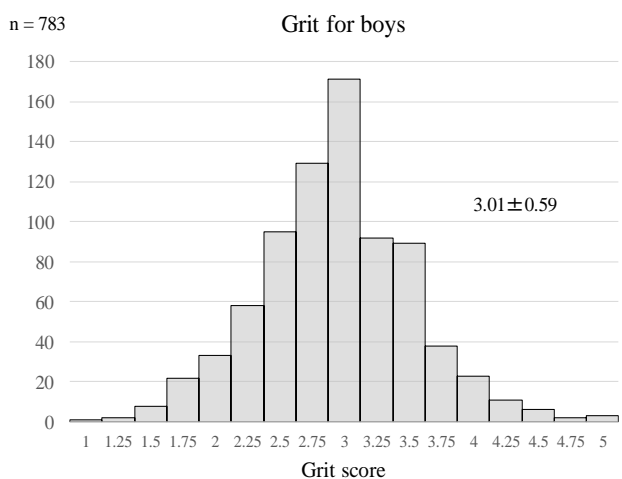

(b)

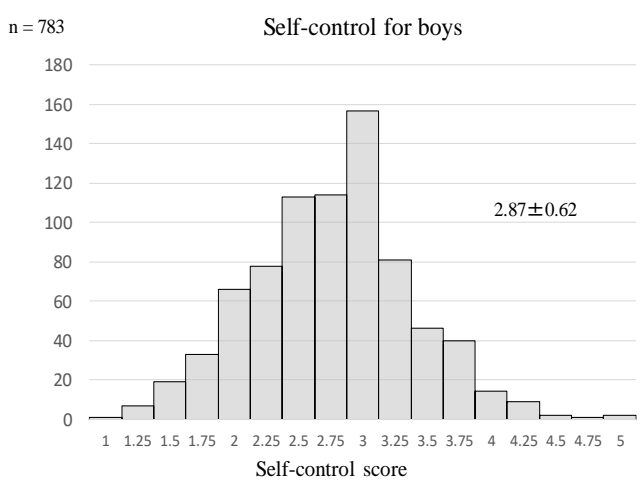

(d)

Figure 1. (a) Grit scores for girls; (b) Grit scores for boys; (c) Self-control scores for girls; (d) Self-control scores 
for boys.

Figure 2 shows the mean scores for self-control and grit according to the quality of the parent-child relationship. According to the Tukey-Kramer HSD test, adolescents with good parent-child relationships exhibited higher NCS scores regardless of the gender of the parent.

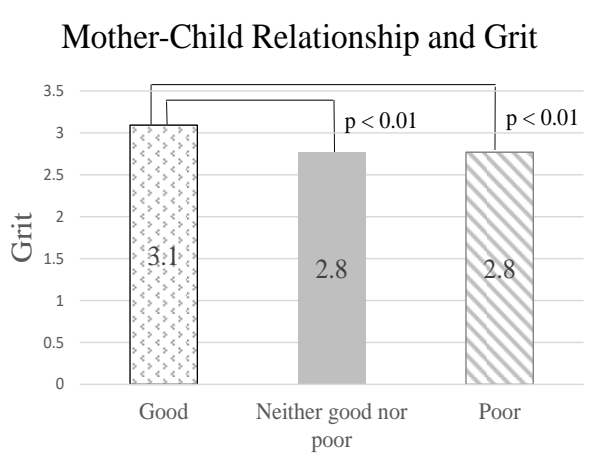

(a)

Mother-Child Relationship and Self-control

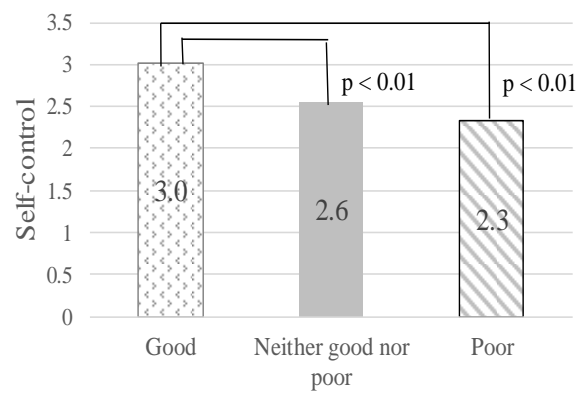

(c)
Father-Child Relationship and Grit

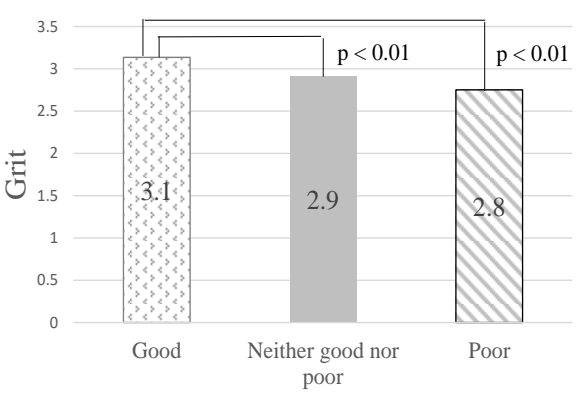

(b)

Father-Child Relationship and Self-control

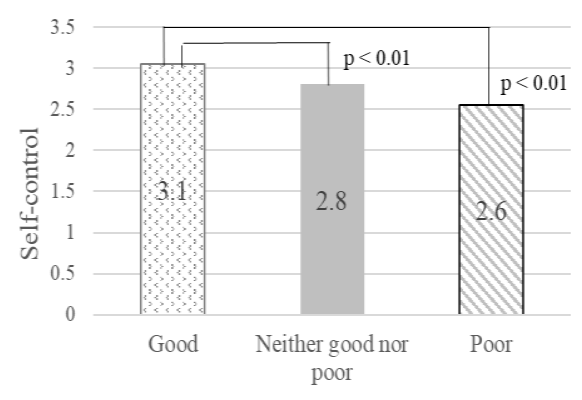

(d)

Figure 2. Mean scores for self-control and grit according to the quality of the parent-child relationship: (a) Mother-child relationship and grit; (b) Father-child relationship and grit; (c) Mother-child relationship and selfcontrol; (d) Father-child relationship and self-control.

Figure 3 shows the mean mental health scores according to the parent-child relationship. Here, good parent-child relationships were significantly associated with better mental health scores. Moreover, mental health scores and NCS were significantly correlated; adolescents with less grit $(r=-0.34, p<$ $0.001)$ and self-control $(\mathrm{r}=-0.34, \mathrm{p}<0.001)$ had lower mental health scores. 
Mother-Child Relationship and Mental Health

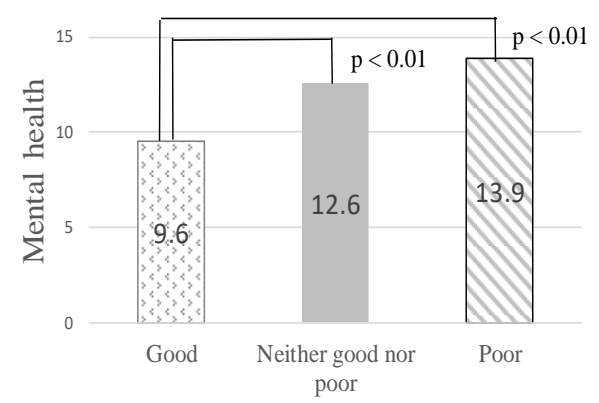

(a)
Father-Child Relationship and Mental Health

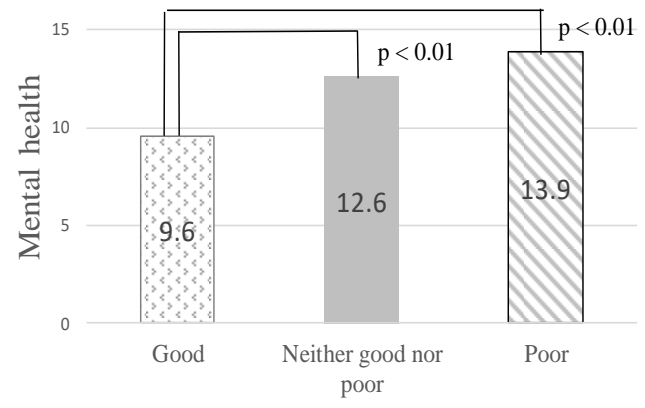

(b)

Figure 3. Mean mental health scores according to the parent-child relationship: (a) Mother-child relationship and mental health; (b) Father-child relationship and mental health.

Finally, regarding the relationship between NCS and adolescent lifestyle parameters (Table 3), all parameters were significantly associated with both grit and self-control ( $p$ $<0.0001)$.

Table 3. Relationship between NCS scores and lifestyle parameters

\begin{tabular}{|c|c|c|c|c|c|c|}
\hline & & $\begin{array}{l}\text { Self-control } \\
\text { (mean } \pm \text { SD) }\end{array}$ & $\mathrm{p}$ value & & $\begin{array}{c}\text { Grit } \\
(\text { mean } \pm S D)\end{array}$ & $\mathrm{p}$ value \\
\hline \multirow{3}{*}{$\begin{array}{l}\text { Academic } \\
\text { achievement }\end{array}$} & Good & $3.2 \pm 0.6$ & & Good & $3.4 \pm 0.6$ & \\
\hline & Average & $2.9 \pm 0.6$ & & Average & $3.0 \pm 0.5$ & \\
\hline & Poor & $2.6 \pm 0.6$ & $<0.0001$ & Poor & $2.7 \pm 0.6$ & $<0.0001$ \\
\hline \multirow{3}{*}{$\begin{array}{l}\text { Goes to school } \\
\text { late }\end{array}$} & Never & $3.0 \pm 0.6$ & & Never & $3.1 \pm 0.6$ & \\
\hline & Once/semester & $2.7 \pm 0.6$ & & Once/semester & $2.8 \pm 0.6$ & \\
\hline & More & $2.5 \pm 0.7$ & $<0.0001$ & More & $2.7 \pm 0.6$ & $<0.0001$ \\
\hline \multirow{3}{*}{$\begin{array}{l}\text { Homework } \\
\text { submission }\end{array}$} & Always can & $3.2 \pm 0.6$ & & Always can & $3.2 \pm 0.5$ & \\
\hline & $\begin{array}{l}\text { Sometimes } \\
\text { cannot }\end{array}$ & $2.7 \pm 0.6$ & & $\begin{array}{l}\text { Sometimes } \\
\text { cannot }\end{array}$ & $2.8 \pm 0.6$ & \\
\hline & Cannot & $2.4 \pm 0.6$ & $<0.0001$ & Cannot & $2.6 \pm 0.5$ & $<0.0001$ \\
\hline \multirow{2}{*}{$\begin{array}{l}\text { Monthly } \\
\text { allowance }\end{array}$} & Use as planned & $3.2 \pm 0.5$ & & Use as planned & $3.2 \pm 0.6$ & \\
\hline & Cannot use & $2.8 \pm 0.6$ & $<0.0001$ & Cannot use & $2.8 \pm 0.6$ & $<0.0001$ \\
\hline \multirow{2}{*}{$\begin{array}{l}\text { Game use } \\
\text { within rules }\end{array}$} & Can use & $3.1 \pm 0.6$ & & Can use & $3.2 \pm 0.6$ & \\
\hline & Cannot use & $2.6 \pm 0.6$ & $<0.0001$ & Cannot use & $2.7 \pm 0.6$ & $<0.0001$ \\
\hline \multirow{3}{*}{$\begin{array}{l}\text { Games on } \\
\text { weekdays }\end{array}$} & $<1 \mathrm{~h}$ & $3.2 \pm 0.6$ & & $<1 \mathrm{~h}$ & $3.3 \pm 0.6$ & \\
\hline & $1-2 \mathrm{~h}$ & $3.0 \pm 0.6$ & & $1-2 \mathrm{~h}$ & $3.1 \pm 0.5$ & \\
\hline & $>2 \mathrm{~h}$ & $2.8 \pm 0.6$ & $<0.0001$ & $>2 \mathrm{~h}$ & $2.9 \pm 0.6$ & $<0.0001$ \\
\hline \multirow{3}{*}{$\begin{array}{l}\text { Game on } \\
\text { weekends }\end{array}$} & $<2 \mathrm{~h}$ & $3.2 \pm 0.6$ & & $<2 \mathrm{~h}$ & $3.3 \pm 0.6$ & \\
\hline & $2-4 \mathrm{~h}$ & $3.0 \pm 0.6$ & & $2-4 \mathrm{~h}$ & $3.1 \pm 0.6$ & \\
\hline & $>4 \mathrm{~h}$ & $2.8 \pm 0.6$ & $<0.0001$ & $>4 \mathrm{~h}$ & $2.9 \pm 0.6$ & $<0.0001$ \\
\hline \multirow{2}{*}{$\begin{array}{l}\text { Child mental } \\
\text { health condition }\end{array}$} & Yes & $2.7 \pm 0.6$ & & Yes & $2.8 \pm 0.5$ & \\
\hline & No & $3.0 \pm 0.6$ & $<0.0001$ & No & $3.1 \pm 0.6$ & $<0.0001$ \\
\hline
\end{tabular}




\begin{tabular}{l|lll|lll}
\hline Mother-child & Good & $3.0 \pm 0.6$ & & Good & $3.1 \pm 0.6$ & \\
relationship & Neither good & $2.6 \pm 0.6$ & & Neither good & $2.8 \pm 0.6$ & \\
& nor poor & & & nor poor & & \\
& Poor & $2.3 \pm 0.6$ & $<0.0001$ & Poor & $2.8 \pm 0.5$ & $<0.0001$ \\
\hline Father-child & Good & $3.1 \pm 0.6$ & & Good & $3.1 \pm 0.6$ & \\
relationship & Neither good & $2.8 \pm 0.6$ & & Neither good & $2.9 \pm 0.6$ & \\
& nor poor & & $<0.0001$ & nor poor & & $<0.0001$ \\
& Poor & $2.6 \pm 0.6$ & & Poor & $2.8 \pm 0.6$ & \\
\hline
\end{tabular}

SD, standard deviation.

\section{Discussion}

To the best of our knowledge, this was the first study to examine the associations between NCS, the parent-child relationship, and mental health among adolescents in Japan. Moreover, few studies have examined the relationship between NCS and lifestyle among Japanese adolescents. Our results indicated that higher NCS scores were associated with better parent-child relationships, better mental health, and more favorable adolescent lifestyle conditions. Previous studies targeting adolescents have focused on the association of academic achievement with higher scores on NCS, such as grit and self-control. This study similarly implies that interventions designed to improve parent-child relationships may promote NCS, increase mental health in children, and promote positive lifestyle conditions. Our study thus provides useful information for parents, educators, and medical professionals.

This study found statistical differences between boys and girls in both self-control and grit. Previous studies have also shown that girls had better grit scores than boys [9, 12, 25] (e.g., $3.43 \pm$ 0.64 for girls, $3.31 \pm 0.70$ for boys, $\mathrm{p}<0.01$ [12]; and $3.49 \pm 0.42$ for girls, $3.29 \pm 0.53$ for boys, $\mathrm{p}<0.05$ [25]). Higher self-control scores were also observed in girls [26]. Girls appear to be more able to control their emotions and behaviors, maintain interest over time, develop good study habits, and steadily pursue goals.

As Heckman discussed, childhood educational interventions are most effective for reaching successful outcomes in school and the labor market [27]; however, this is insufficient. Parent-child interactions are also considered important for developing NCS. Thus, interventions encouraging strong attachment and responsive parenting facilitate children's development of NCS [6, 27]. For example, Heckman's Perry Preschool program was successful because it not only provided education to treatment-group children but also taught parents about appropriate parent-child interactions during 90-minute weekly home visits over a 2-year period [28]. Family interventions of this type may produce long-term positive effects that are useful for children in their later lives [1]. However, such effects are underestimated when compared to those of childhood education. Our study results support the idea that family interventions should focus on good parent-child relationships by establishing stable attachments; these conditions may help children develop NCS for the promotion of a successful life.

This study supported the results of previous research indicating that students with higher grit and self-control scores were more likely to demonstrate better academic performance [7-11]. Regarding school lifestyle factors, grittier students showed overall better school attendance [7]. Students with better NCS in our study tended to arrive at school on time. Moreover, our study uniquely found that NCS were associated with lifestyle as characterized by homework submission 
rates, playing games under restrictions, and responsible use of monthly allowance. Favorable lifestyles both at home and in school were thus observed for adolescents with better NCS.

This study was also the first to examine adolescent mental health in the context of NCS. While previous research has examined mental health among university students in relation to the NCS $[29,30]$, adolescents had not yet been considered. In addition, research has indicated that grit and school satisfaction are positively associated among adolescents [12], but few studies have examined how these items relate to mental health. Here, we found significant correlations between mental health and NCS (i.e., for both self-control and grit). Previous studies found that primary school students showed higher scores on both self-control and grit than did secondary school students [12, 26]. However, higher NCS scores are expected among older and more mature children [31]. On the other hand, adolescents tend to have difficulty controlling their impulses and making appropriate decisions under frustrating conditions. They are thus expected to behave more impulsively than younger children and feel depressed when their objectives are not met [32,33].

In reality, secondary school students exhibit more depressive tendencies than elementary school students [34]; depressive symptoms tend to increase from childhood through adolescence before peaking between 15 and 17 years of age (and then decrease in young adulthood) [35]. These symptoms may increase during adolescence because of changing school environments and new sources of stress, such as those related to making new friends and taking exams [35]. Puberty may also cause difficulty when interacting with parents. NCS may thus decrease in quality during adolescence when compared with childhood. This is in accordance with the increase in depressive symptoms seen during adolescence, which may help explain how poor mental health affects NCS levels. This study revealed that good parent-child relationships were significantly associated with good mental health, thereby implying that adolescents can achieve good mental health through good parent-child relationships, even during puberty, and will consequently be able to maintain or improve their NCS.

This study has several limitations. First, it used a cross-sectional design. We therefore cannot make any inferences regarding the causality of the observed associations between NCS and the parent-child relationship, child mental health, or lifestyle. Second, selection bias may have influenced our results. The number of respondents that had graduated from university was twice the Japanese national average (http://www.stat.go.jp/data/kokusei/2010/usersg/wakatta.html\#jump2 accessed March, 2019) for both mothers and fathers. This may be because this study was conducted on the internet. Participants were thus likely to be more computer-literate and educated. Moreover, most mothers in this study had good or very good relationships with their children. This could be because mothers were required to ask their children to participate in the study, thus implying the existence of a good relationship. Third, the fathers did not participate in this study; therefore, there is a possibility of a bias in terms of the father-child relationship results.

Despite these limitations, this study provides useful information for families with adolescents, child educators, and pediatricians. Results indicated that NCS and parent-child relationships were significantly associated, thereby suggesting that improved parent-child relationships can result in better NCS development. Better NCS should also boost academic performance while promoting favorable lifestyle conditions for adolescents. Future studies should thus assess parental interventions to determine their effectiveness for children and how to adapt them according to age.

\section{Conclusions}


This study indicated that higher NCS scores were significantly associated with good parentchild relationships, favorable lifestyles, and better mental health among adolescents. Our results imply that good parent-child relationships facilitate the development of NCS in adolescents, thereby promoting good lifestyles both in school and at home.

Author contributions: H.S. conceptualized the study; H.S. and T.K. designed the study; H.S. and N.M. collected and analyzed data; N.M. coordinated and supervised the data collection; H.S. drafted the initial manuscript; N.M. and T.K. critically reviewed and revised the manuscript; and all authors approved the final manuscript as submitted and agreed to be accountable for all aspects of the work.

Funding: This study was generously funded by the Health and Welfare Department, Kagawa Prefectural Government, Takamatsu, Kagawa.

Acknowledgments: We offer special thanks to the mothers and children who participated in this study.

Conflicts of Interest: The authors declare no conflicts of interest.

\section{References}

1. Heckman, J.J., Kautz, T. Hard evidence on soft skills. Labour. Econ. 2012, 19, 451-464.

2. Heckman, J.J., Stixrud, J., Urza, S. The effects of cognitive and noncognitive abilities on labor market outcomes and social behavior. Labour. Econ. 2006, 24, 411-482.

3. John OP, Srivastava S. The Big Five trait taxonomy: History, measurement and theoretical perspectives. In Handbook of Personality: Theory and Research; Pervin, L.A., and John, O.P., Eds.; The Guilford Press: New York, 1999; pp. 102-138.

4. Gutman, L.M., Schoon, I. The impact of non-cognitive skills on outcomes for young people. Education Endowment Foundation, London, 2013.

5. Duckworth, A, $\mathrm{L}_{\text {, }}$ Peterson, C., Matthews, M.D., Kelly, D.R. Grit: perseverance and passion for long-term goals. J. Pers. Soc. Psychol. 2007, 92, 1087.

6. Kautz, T., Heckman, J.J., Diris, R., Weel B., Borghans, L. Fostering and measuring skills: Improving cognitive and non-cognitive skills to promote lifetime success. OECD, Paris, 2014.

7. Cosgrove, J.M., Chen, Y.T., Castelli, D.M. Physical fitness, grit, school attendance, and academic performance among adolescents. BioMed. Res. Int. 2018, e9801258.

8. Hagger, M.S., Hamilton, K. Grit and self-discipline as predictors of effort and academic attainment. Br. J. Educ. Psychol. 2019, 89(2), 324-342.

9. Rimfeld, K., Kovas, Y., Dale, P.S., Plomin, R. True grit and genetics: Predicting academic achievement from personality. J. Pers. Soc. Psychol. 2016, 111, 780-789.

10. Duckworth, A.L., Seligman, M.E., Martin, E.P. Self-discipline outdoes IQ in predicting academic performance of adolescents. Psychol. Sci. 2005, 16, 939-944.

11. Duckworth, A.L., Tsukayama, E., Kirby, T.A. Is it really self-control? Examining the predictive power of the delay of gratification task. Pers. So.c Psycho.l Bull. 2013, 39, 843-55.

12. Oriol, X., Miranda, R., Oyanedel, J.C., Torres, J. The role of self-control and grit in domains of school success in students of primary and secondary school. Front. Psychol. 2017, 8, 1716.

13. Duckworth, A.L., Gross, J.J. Self-control and grit: Related but separable determinants of success. Curr. Dir. Psychol. Sci. 2014, 23, 319-325.

14. Moffitt, T.E., Arseneault, L., Belsky, D., Dickson, N., Hancox, R.J., Harrington, H., Houts, R., Poulton, R., Roberts, B.W., Ross, S., Sears, M.R., Murray Thomson, W., Caspi, A. A gradient of childhood self-control 
predicts health, wealth, and public safety. PNAS. 2011, 108, 2693-2698.

15. Heckman, J.J. Giving Kids a Fair Chance. The MIT Press, Massachusetts, USA, 2013.

16. Campbell, F., Ramey, C. Effects of early intervention on intellectual and academic achievement: A followup study of children from low-income families program title: Carolina Abecedarian Project. Child Dev 1994, 65, 684-698.

17. Smithers, L.G., Sawyer, A.C.P., Chittleborough, C.R., Davies, N., Smith, G.D., Lynch, J. A systematic review and meta-analysis of effects of early life non-cognitive skills on academic, psychosocial, cognitive and health outcomes. Nat. Hum. Behav. 2018, 2, 867-880.

18. Hsin, A., Xie, Y. Life-course changes in the mediation of cognitive and non-cognitive skills for parental effects on children's academic achievement. Soc. Sci. Res. 2017, 63, 150-165.

19. Duckworth, A.L., Quinn, P.D. Development and validation of the short grit scale (Grit-S). J. Pers. Assess. 2009, 91, 166-174.

20. Nishikawa, K., Okugami, S., Amemiya, T. Development of the Japanese Short Grit Scale (Grit-S). Jpn. J. Pers. 2015, 24, 167-169 (in Japanese).

21. Tangney, J.P., Baumeister, R.F., Boone, A.L. High self-control predicts good adjustment, less pathology, better grades, and interpersonal success. J. Pers. 2004, 72, 271-324.

22. Ozaki, Y., Goto, T., Kobayashi, M., Kutsuzawa, G. Reliability and validity of the Japanese translation of Brief Self-Control Scale (BSCS-J). Jpn. J. Psychol. 2016, 87, 144-154 (in Japanese).

23. Birleson, P. The validity of depressive disorder in childhood and the development of a self-rating scale: A research report. J. Child. Psychol. Psychiatry. 1981, 22, 73-88.

24. Murata, T., Shimizu, A., Mori, Y., Oshima, S. Childhood depressive state in the school situation. Consideration from the Birleson's Scale. Jpn. J. Psychiatry. 1996, 1, 131-138 (in Japanese).

25. Christensen, R., Knezek, G. Comparative measures of grit, tenacity and perseverance. Int. J. Learn. Teach. Educ. Res. 2014, 8, 16-30.

26. Raffaelli, M., Crockett, L.J., Shen, Y.L. Developmental stability and change in self-regulation from childhood to adolescence. J. Genet. Psychol. 2005, 166, 54-75.

27. Scorza, P., Araya, R., Wuermli, A.J., Betancourt, T.S. Towards clarity in research on "non-cognitive" skills: Linking executive functions, self-regulation, and economic development to advance life outcomes for children, adolescents and youth globally. Hum. Dev. 2016, 58, 313-317.

28. Heckman, J., Pinto, R., Savelyev, P. Understanding the mechanisms through which an influential early childhood program boosted adult outcomes. Am. Econ. Rev. 2013, 103, 2052-2086.

29. Kannangara, C.S., Allen, R.E., Waugh, G., Nahar, N., Khan, S.Z.N., Rogerson, S., Carson, J. All that glitters is not grit: Three studies of grit in university students. Front. Psychol. 2018, 9, 1539.

30. Musumari, P.M., Tangmunkongvorakul, A., Srithanaviboonchail, K., Techasrivichien, T., Suguimoto, S.P., Ono-Kihara, M. Grit is associated with lower level of depression and anxiety among university students in Chiang Mai, Thailand: A cross-sectional study. PLoS. ONE. 2018, 13, e0209121.

31. Carneiro, P., Crawford, C., Goodman, A. The impact of early cognitive and non-cognitive skills on later outcomes 2007; CEE Discussion paper 0092. Centre for the Economics of Education, London School of Economics, London, 2007.

32. Bell, C.C., McBride, D.F. Affect regulation and prevention of risky behaviors. JAMA. 2010, 304, 565-566.

33. Casey, B., Caudle, K. The teenage brain: Self-control. Curr. Dir. Psychol. Sci. 2013, 22, 82-87.

34. Longa, S., Rogers, M.L., Gjelsvik, A. The influence of depression status on weekly exercise in children ages 6 to 17 years. Prev. Med. Rep. 2019, 13, 199-204. 
35. Perou, R., Bitsko, R.H., Blumberg, S.J., Pastor, P., Ghandour, R.M., Gfroerer, J.C., Hedden, S.L., Crosby, A.E., Visser, S.N., Schieve, L.A., Parks, S.E., Hall, J.E., Brody, D., Simile, C.M., Thompson, W.W., Baio, J., Avenevoli, S., Kogan, M.D., Huang, L.N., Centers for Disease Control and Prevention (CDC). Mental health surveillance among children-United States, 2005-2011. MMWR Suppl. 2013, 62, 1-35. 